\title{
Weak and strong convergence theorems of implicit iteration process on Banach spaces
}

\author{
Lai-Jiu Lin $^{1 *}$, Chih-Sheng Chuang ${ }^{1}$ and Zenn-Tsun Yu ${ }^{2}$
}

\author{
* Correspondence: maljin@cc.ncue. \\ edu.tw \\ 'Department of Mathematics, \\ National Changhua University of \\ Education, Changhua 50058, \\ Taiwan \\ Full list of author information is \\ available at the end of the article
}

\begin{abstract}
In this article, we first consider weak convergence theorems of implicit iterative processes for two nonexpansive mappings and a mapping which satisfies condition (C). Next, we consider strong convergence theorem of an implicit-shrinking iterative process for two nonexpansive mappings and a relative nonexpansive mapping on Banach spaces. Note that the conditions of strong convergence theorem are different from the strong convergence theorems for the implicit iterative processes in the literatures. Finally, we discuss a strong convergence theorem concerning two nonexpansive mappings and the resolvent of a maximal monotone operator in a Banach space.
\end{abstract}

\section{Introduction}

Let $E$ be a Banach space, and let $C$ be a nonempty closed convex subset of $E$. A mapping $T: C \rightarrow E$ is nonexpansive if $\|T x-T y\| \leq\|x-y\|$ for every $x, y \in C$. Let $F(T):=$ $\{x \in C: x=T x\}$ denote the set of fixed points of $T$. Besides, a mapping $T: C \rightarrow E$ is quasinonexpansive if $F(T) \neq \varnothing$ and $\|T x-y\| \leq\|x-y\|$ for all $x \in C$ and $y \in F(T)$.

In 2008, Suzuki [1] introduced the following generalized nonexpansive mapping on Banach spaces. A mapping $T: C \rightarrow E$ is said to satisfy condition $(C)$ if for all $x, y \in C$,

$$
\frac{1}{2}\|x-T x\| \leq\|x-y\| \Rightarrow\|T x-T y\| \leq\|x-y\| .
$$

In fact, every nonexpansive mapping satisfies condition $(C)$, but the converse may be false [1, Example 1]. Besides, if $T: C \rightarrow E$ satisfies condition $(C)$ and $F(T) \neq \emptyset$, then $T$ is a quasinonexpansive mapping. However, the converse may be false [1, Example 2].

Construction of approximating fixed points of nonlinear mappings is an important subject in the theory of nonlinear mappings and its applications in a number of applied areas.

Let $C$ be a nonempty closed convex subset of a real Hilbert space $H$, and let $T: C \rightarrow$ $C$ be a mapping. In 1953, Mann [2] gave an iteration process:

$$
x_{n+1}=\alpha_{n} x_{n}+\left(1-\alpha_{n}\right) T x_{n}, \quad n \geq 0,
$$

where $x_{0}$ is taken in $C$ arbitrarily, and $\left\{\alpha_{n}\right\}$ is a sequence in $[0,1]$.

In 2001, Soltuz [3] introduced the following Mann-type implicit process for a nonexpansive mapping $T: C \rightarrow C$ :

$$
x_{n}=\alpha_{n} x_{n-1}+\left(1-\alpha_{n}\right) T x_{n}, \quad n \in \mathbb{N},
$$

(c) 2011 Lin et al; licensee Springer. This is an Open Access article distributed under the terms of the Creative Commons Attribution License (http://creativecommons.org/licenses/by/2.0), which permits unrestricted use, distribution, and reproduction in any medium, provided the original work is properly cited. 
where $x_{0}$ is taken in $C$ arbitrarily, and $\left\{t_{n}\right\}$ is a sequence in $[0,1]$.

In 2001, $\mathrm{Xu}$ and Ori [4] have introduced an implicit iteration process for a finite family of nonexpansive mappings. Let $T_{1}, T_{2}, \ldots, T_{N}$ be $N$ self-mappings of $C$ and suppose that $F:=\cap_{i=1}^{N} F\left(T_{i}\right) \neq \emptyset$, the set of common fixed points of $T_{i}, i=1,2, \ldots, N$. Let $I$ : $=\{1,2, \ldots, N\} . \mathrm{Xu}$ and Ori [4] gave an implicit iteration process for a finite family of nonexpansive mappings:

$$
x_{n}=t_{n} x_{n-1}+\left(1-t_{n}\right) T_{n} x_{n}, \quad n \in \mathbb{N},
$$

where $x_{0}$ is taken in $C$ arbitrarily, $\left\{t_{n}\right\}$ is a sequence in $[0,1]$, and $T_{k}=T_{k \bmod N}$. (Here the mod $N$ function takes values in $I$.) And they proved the weak convergence of process (1.3) to a common fixed point in the setting of a Hilbert space.

In 2010, Khan et al. [5] presented an implicit iterative process for two nonexpansive mappings in Banach spaces. Let $E$ be a Banach space, and let $C$ be a nonempty closed convex subset of $E$, and let $T, S: C \rightarrow C$ be two nonexpansive mappings. Khan et al. [5] considered the following implicit iterative process:

$$
x_{n}=\alpha_{n} x_{n-1}+\beta_{n} S x_{n}+\gamma_{n} T x_{n}, \quad n \in \mathbb{N},
$$

where $\left\{\alpha_{n}\right\},\left\{\beta_{n}\right\}$, and $\left\{\gamma_{n}\right\}$ are sequences in $[0,1]$ with $\alpha_{n}+\beta_{n}+\gamma_{n}=1$.

Motivated by the above works in [5], we want to consider the following implicit iterative process. Let $E$ be a Banach space, $C$ be a nonempty closed convex subset of $E$, and let $T_{1}, T_{2}: C \rightarrow C$ be two nonexpansive mappings, and let $S: C \rightarrow C$ be a mapping which satisfy condition $(C)$. We first consider the weak convergence theorems for the following implicit iterative process:

$$
\left\{\begin{array}{l}
x_{0} \in C \text { chosen arbitrary, } \\
x_{n}=a_{n} x_{n-1}+b_{n} S x_{n-1}+c_{n} T_{1} x_{n}+d_{n} T_{2} x_{n}
\end{array}\right.
$$

where $\left\{a_{n}\right\},\left\{b_{n}\right\},\left\{c_{n}\right\}$, and $\left\{d_{n}\right\}$ are sequences in $[0,1]$ with $a_{n}+b_{n}+c_{n}+d_{n}=1$.

Next, we also consider weak convergence theorems for another implicit iterative process:

$$
\left\{\begin{array}{l}
x_{0} \in C \text { chosen arbitrary } \\
y_{n}=a_{n} x_{n-1}+b_{n} T_{1} y_{n}+c_{n} T_{2} y_{n} \\
x_{n}=d_{n} y_{n}+\left(1-d_{n}\right) S y_{n}
\end{array}\right.
$$

where $\left\{a_{n}\right\},\left\{b_{n}\right\},\left\{c_{n}\right\}$, and $\left\{d_{n}\right\}$ are sequences in $[0,1]$ with $a_{n}+b_{n}+c_{n}=1$.

In fact, for the above implicit iterative processes, most researchers always considered weak convergence theorems, and few researchers considered strong convergence theorem under suitable conditions. For example, one can see [5-7]. However, some conditions are not natural. For this reason, we consider the following shrinking-implicit iterative processes and study the strong convergence theorem. Let $\left\{x_{n}\right\}$ be defined by

$$
\left\{\begin{array}{l}
x_{0} \in C \text { chosen arbitrary and } C_{0}=D_{0}=C, \\
y_{n}=a_{n} x_{n-1}+b_{n} T_{1} y_{n}+c_{n} T_{2} y_{n} \\
z_{n}=J^{-1}\left(d_{n} J y_{n}+\left(1-d_{n}\right) J S y_{n}\right) \\
C_{n}=\left\{z \in C_{n-1}: \phi\left(z, z_{n}\right) \leq \phi\left(z, y_{n}\right)\right\} \\
D_{n}=\left\{z \in D_{n-1}:\left\|y_{n}-z\right\| \leq\left\|x_{n-1}-z\right\|\right\} \\
x_{n}=\Pi_{C_{n} \cap D_{n}} x_{0}
\end{array}\right.
$$


where $\left\{a_{n}\right\},\left\{b_{n}\right\},\left\{c_{n}\right\}$, and $\left\{d_{n}\right\}$ are sequences in $(0,1)$ with $a_{n}+b_{n}+c_{n}=1$.

In this article, we first consider weak convergence theorems of implicit iterative processes for two nonexpansive mappings and a mapping which satisfy condition $(C)$. And we generalize Khan et al.'s result [5] as special case. Next, we consider strong convergence theorem of an implicit-shrinking iterative process for two non-expansive mappings and a relative nonexpansive mapping on Banach spaces. Note that the conditions of strong convergence theorem are different from the strong convergence theorems for the implicit iterative processes in the literatures. Finally, we discuss a strong convergence theorem concerning two nonexpansive mappings and the resolvent of a maximal monotone operator in a Banach space.

\section{Preliminaries}

Throughout this article, let $\mathbb{N}$ and $\mathbb{R}$ be the sets of all positive integers and real numbers, respectively. Let $E$ be a Banach space and let $E^{*}$ be the dual space of $E$. For a sequence $\left\{x_{n}\right\}$ of $E$ and a point $x \in E$, the weak convergence of $\left\{x_{n}\right\}$ to $x$ and the strong convergence of $\left\{x_{n}\right\}$ to $x$ are denoted by $x_{n} \rightarrow x$ and $x_{n} \rightarrow x$, respectively.

A Banach space $E$ is said to satisfy Opial's condition if $\left\{x_{n}\right\}$ is a sequence in $E$ with $x_{n}$ $\rightarrow x$, then

$$
\limsup _{n \rightarrow \infty}\left\|x_{n}-x\right\|<\limsup _{n \rightarrow \infty}\left\|x_{n}-y\right\|, \quad \forall y \in E, y \neq x .
$$

Let $E$ be a Banach space. Then, the duality mapping $J: E \multimap E^{*}$ is defined by

$$
J x:\left\{x^{*} \in E^{*}:\left\langle x, x^{*}\right\rangle=\|x\|^{2}=\left\|x^{*}\right\|^{2}\right\}, \quad \forall x \in E .
$$

Let $S(E)$ be the unit sphere centered at the origin of $E$. Then, the space $E$ is said to be smooth if the limit

$$
\lim _{t \rightarrow 0} \frac{\|x+t y\|-\|x\|}{t}
$$

exists for all $x, y \in S(E)$. It is also said to be uniformly smooth if the limit exists uniformly in $x, y \in S(E)$. A Banach space $E$ is said to be strictly convex if $\left\|\frac{x+y}{2}\right\|<1$ whenever $x, y \in S(E)$ and $x \neq y$. It is said to be uniformly convex if for each $\varepsilon \in(0,2]$, there exists $\delta>0$ such that $\left\|\frac{x+y}{2}\right\|<1-\delta$ whenever $x, y \in S(E)$ and $\|x-y\| \geq \varepsilon$. Furthermore, we know that [8]

(i) if $E$ in smooth, then $J$ is single-valued;

(ii) if $E$ is reflexive, then $J$ is onto;

(iii) if $E$ is strictly convex, then $J$ is one-to-one;

(iv) if $E$ is strictly convex, then $J$ is strictly monotone;

(v) if $E$ is uniformly smooth, then $J$ is uniformly norm-to-norm continuous on each bounded subset of $E$.

A Banach space $E$ is said to have Kadec-Klee property if a sequence $\left\{x_{n}\right\}$ of $E$ satisfying that $x_{n} \rightarrow x$ and $\left\|x_{n}\right\| \rightarrow\|x\|$, then $x_{n} \rightarrow x$. It is known that if $E$ uniformly convex, then $E$ has the Kadec-Klee property [8]. 
Let $E$ be a smooth, strictly convex and reflexive Banach space and let $C$ be a nonempty closed convex subset of $E$. Throughout this article, define the function $\varphi: C \times C$ $\rightarrow \mathbb{R}$ by

$$
\phi(x, y):=\|x\|^{2}-2\langle x, J y\rangle+\|y\|^{2}, \quad \forall x, y \in E .
$$

Observe that, in a Hilbert space $H, \varphi(x, y)=\|x-y\|^{2}$ for all $x, y \in H$. Furthermore, for each $x, y, z, w \in E$, we know that:

(1) $(\|x\|-\|y\|)^{2} \leq \varphi(x, y) \leq(\|x\|+\|y\|)^{2}$;

(2) $\varphi(x, y) \geq 0$;

(3) $\varphi(x, y)=\varphi(x, z)+\varphi(z, y)+2\langle x-z, J z-J y\rangle$;

(4) $2\langle x-y, J z-J w\rangle=\varphi(x, w)+\varphi(y, z)-\varphi(x, z)-\varphi(y, w)$;

(5) if $E$ is additionally assumed to be strictly convex, then $\phi(x, y)=0$ if and only if $x=y ;$

(6) $\varphi\left(x, J^{-1}(\lambda J y+(1-\lambda) J z)\right) \leq \lambda \varphi(x, y)+(1-\lambda) \varphi(x, z)$.

Lemma 2.1. [9] Let $E$ be a uniformly convex Banach space and let $r>0$. Then, there exists a strictly increasing, continuous, and convex function $g:[0,2 r] \rightarrow[0, \infty)$ such that $g(0)=0$ and

$$
\|a x+b y+c z+d w\|^{2} \leq a|| x\left\|^{2}+b\right\| y\left\|^{2}+c\right\| z\left\|^{2}+d\right\| w \|^{2}-a b g(\|x-y\|)
$$

for all $x, y, z, w \in B_{r}$ and $a, b, c, d \in[0,1]$ with $a+b+c+d=1$, where $B_{r}:=\{z \in$ $E:|| z|| \leq r\}$.

Lemma 2.2. [10] Let $E$ be a uniformly convex Banach space and let $r>0$. Then, there exists a strictly increasing, continuous, and convex function $g:[0,2 r] \rightarrow[0, \infty)$ such that $g(0)=0$ and

$$
\phi\left(x, J^{-1}(\lambda J y+(1-\lambda) J z)\right) \leq \lambda \phi(x, y)+(1-\lambda) \phi(x, z)-\lambda(1-\lambda) g(|| J y-J z||)
$$

for all $x, y, z \in B_{r}$ and $\lambda \in[0,1]$, where $B_{r}:=\{z \in E:\|z\| \leq r\}$.

Lemma 2.3. [11] Let $E$ be a uniformly convex Banach space, let $\left\{\alpha_{n}\right\}$ be a sequence of real numbers such that $0<b \leq \alpha_{n} \leq c<1$ for all $n \in \mathbb{N}$, and let $\left\{x_{n}\right\}$ and $\left\{y_{n}\right\}$ be sequences of $E$ such that $\lim \sup _{n \rightarrow \infty}\left\|x_{n}\right\| \leq a, \lim \sup _{n \rightarrow \infty}\left\|y_{n}\right\| \leq a$, and $\lim _{n \rightarrow \infty} \|$ $\alpha_{n} x_{n}+\left(1-\alpha_{n}\right) y_{n} \|=a$ for some $a \geq 0$. Then, $\lim _{n \rightarrow \infty}|| x_{n}-y_{n} \|=0$.

Lemma 2.4. [12] Let $E$ be a smooth and uniformly convex Banach space, and let $\left\{x_{n}\right\}$ and $\left\{y_{n}\right\}$ be sequences in $E$ such that either $\left\{x_{n}\right\}$ or $\left\{y_{n}\right\}$ is bounded. If $\lim _{n \rightarrow \infty} \varphi\left(x_{n}, y_{n}\right)$ $=0$, then $\lim _{n \rightarrow \infty}|| x_{n}-y_{n} \|=0$.

Remark 2.1. [13] Let $E$ be a uniformly convex and uniformly smooth Banach space. If $\left\{x_{n}\right\}$ and $\left\{y_{n}\right\}$ are bounded sequences in $E$, then

$$
\lim _{n \rightarrow \infty} \phi\left(x_{n}, y_{n}\right)=0 \Leftrightarrow \lim _{n \rightarrow \infty}\left\|x_{n}-y_{n}\right\|=0 \Leftrightarrow \lim _{n \rightarrow \infty}\left\|J x_{n}-J y_{n}\right\|=0 .
$$

Let $C$ be a nonempty closed convex subset of a smooth, strictly convex, and reflexive Banach space $E$. For an arbitrary point $x$ of $E$, the set 


$$
\left\{z \in C: \phi(z, x)=\min _{y \in C} \phi(y, x)\right\}
$$

is always nonempty and a singleton [14]. Let us define the mapping $\Pi_{C}$ from $E$ onto $C$ by $\Pi_{C} x=z$, that is,

$$
\phi\left(\Pi_{C} x, x\right)=\min _{y \in C} \phi(y, x)
$$

for every $x \in E$. Such $\Pi_{C}$ is called the generalized projection from $E$ onto $C$ [14].

Lemma 2.5. $[14,15]$ Let $C$ be a nonempty closed convex subset of a smooth, strictly convex, and reflexive Banach space $E$, and let $(x, z) \in E \times C$. Then:

(i) $z=\Pi_{C} x$ if and only if $\langle y-z, J x-J z\rangle \leq 0$ for all $y \in C$;

(ii) $\varphi\left(z, \Pi_{C} x\right)+\varphi\left(\Pi_{C} x, x\right) \leq \varphi(z, x)$.

Lemma 2.6. [16] Let $E$ be a uniformly convex Banach space, $C$ be a nonempty closed convex subset of $E$ and $T: C \rightarrow C$ is a nonexpansive mapping. Let $\left\{x_{n}\right\}$ be a sequence in $C$ with $x_{n}-x \in C$ and $\lim _{n \rightarrow \infty}|| x_{n}-T x_{n} \|=0$. Then, $T x=x$.

Lemma 2.7. [1] Let $C$ be a nonempty subset of a Banach space $E$ with the Opial property. Assume that $T: C \rightarrow E$ satisfies condition $(C)$. Let $\left\{x_{n}\right\}$ be a sequence in $C$ with $x_{n} \rightarrow x \in C$ and $\lim _{n \rightarrow \infty}\left\|x_{n}-T x_{n}\right\|=0$. Then, $T x=x$.

Lemma 2.8. [1] Let $T$ be a mapping on a closed subset $C$ of a Banach space $E$. Assume that $T$ satisfies condition $(C)$. Then, $F(T)$ is a closed set. Moreover, if $E$ is strictly convex and $C$ is convex, then $F(T)$ is also convex.

Lemma 2.9. [17] Let $C$ be a nonempty closed convex subset of a strictly convex Banach space $E$, and $T: C \rightarrow C$ be a nonexpansive mapping. Then, $F(T)$ is a closed convex subset of $C$.

\section{Weak convergence theorems}

Lemma 3.1. Let $E$ be a uniformly convex Banach space, $C$ be a nonempty closed convex subset of $E$, and let $T_{1}, T_{2}: C \rightarrow C$ be two nonexpansive mappings, and let $S$ : $C$ $\rightarrow C$ be a mapping with condition $(C)$. Let $\left\{a_{n}\right\},\left\{b_{n}\right\},\left\{c_{n}\right\}$, and $\left\{d_{n}\right\}$ be sequences with $0<a \leq a_{n}, b_{n}, c_{n}, d_{n} \leq b<1$ and $a_{n}+b_{n}+c_{n}+d_{n}=1$. Suppose that $\Omega:=F(S) \cap F\left(T_{1}\right) \cap F\left(T_{2}\right) \neq \emptyset$. Define a sequence $\left\{x_{n}\right\}$ by

$$
\left\{\begin{array}{l}
x_{0} \in C \text { chosen arbitrary, } \\
x_{n}=a_{n} x_{n-1}+b_{n} S x_{n-1}+c_{n} T_{1} x_{n}+d_{n} T_{2} x_{n} .
\end{array}\right.
$$

Then, we have:

(i) $\lim _{n \rightarrow \infty}\left\|x_{n}-p\right\|$ exists for each $p \in \Omega$.

(ii) $\lim _{n \rightarrow \infty}\left\|x_{n}-S x_{n}\right\|=\lim _{n \rightarrow \infty}\left\|x_{n}-T_{1} x_{n}\right\|=\lim _{n \rightarrow \infty}\left\|x_{n}-T_{2} x_{n}\right\|=0$.

Proof. First, we show that $\left\{x_{n}\right\}$ is well-defined. Now, let $f(x):=a_{1} x_{0}+b_{1} S x_{0}+c_{1} T_{1} x$ $+d_{1} T_{2} x$. Then,

$$
\|f(x)-f(y)\| \leq c_{1}\left\|T_{1} x-T_{1} y\right\|+d_{1}\left\|T_{2} x-T_{2} y\right\| \leq\left(c_{1}+d_{1}\right)\|x-y\| \leq(1-2 a)\|x-y\| .
$$


By Banach contraction principle, the existence of $x_{1}$ is established. Similarly, the existence of $\left\{x_{n}\right\}$ is well-defined.

(i) For each $p \in \Omega$ and $n \in \mathbb{N}$, we have:

$$
\begin{aligned}
& \left\|x_{n}-p\right\| \\
\leq & a_{n}\left\|x_{n-1}-p\right\|+b_{n}\left\|S x_{n-1}-p\right\|+c_{n}\left\|T_{1} x_{n}-p\right\|+d_{n}\left\|T_{2} x_{n}-p\right\| \\
\leq & a_{n}\left\|x_{n-1}-p\right\|+b_{n}\left\|x_{n-1}-p\right\|+\left(c_{n}+d_{n}\right)\left\|x_{n}-p\right\| .
\end{aligned}
$$

This implies that $\left(1-c_{n}-d_{n}\right)|| x_{n}-p\left\|\leq\left(a_{n}+b_{n}\right)|| x_{n-1}-p\right\|$. Hence, $\left\|x_{n}-p\right\| \leq \| x_{n-1^{-}}$ $p\left\|, \lim _{n \rightarrow \infty}\right\| x_{n}-p \|$ exists, and $\left\{x_{n}\right\}$ is a bounded sequence.

(ii) Take any $p \in \Omega$ and let $p$ be fixed. Suppose that $\lim _{n \rightarrow \infty}\left\|x_{n}-p\right\|=d$.

Clearly, $\limsup _{n \rightarrow \infty}\left\|T_{2} x_{n}-p\right\| \leq d$, and we have:

$$
\begin{aligned}
& \lim _{n \rightarrow \infty}\left\|x_{n}-p\right\| \\
= & \lim _{n \rightarrow \infty}\left\|a_{n} x_{n-1}+b_{n} S x_{n-1}+c_{n} T_{1} x_{n}+d_{n} T_{2} x_{n}-p\right\| \\
= & \lim _{n \rightarrow \infty}\left\|\left(1-d_{n}\right)\left[\frac{a_{n}}{1-d_{n}}\left(x_{n-1}-p\right)+\frac{b_{n}}{1-d_{n}}\left(S x_{n-1}-p\right)+\frac{c_{n}}{1-d_{n}}\left(T_{1} x_{n}-p\right)\right]+d_{n}\left(T_{2} x_{n}-p\right)\right\| .
\end{aligned}
$$

Besides,

$$
\begin{aligned}
& \limsup _{n \rightarrow \infty}\left\|\frac{a_{n}}{1-d_{n}}\left(x_{n-1}-p\right)+\frac{b_{n}}{1-d_{n}}\left(S x_{n-1}-p\right)+\frac{c_{n}}{1-d_{n}}\left(T_{1} x_{n}-p\right)\right\| \\
\leq & \limsup _{n \rightarrow \infty} \frac{a_{n}}{1-d_{n}}\left\|x_{n-1}-p\right\|+\frac{b_{n}}{1-d_{n}}\left\|S x_{n-1}-p\right\|+\frac{c_{n}}{1-d_{n}}\left\|T_{1} x_{n}-p\right\| \\
\leq & \limsup _{n \rightarrow \infty} \frac{a_{n}}{1-d_{n}}\left\|x_{n-1}-p\right\|+\frac{b_{n}}{1-d_{n}}\left\|S x_{n-1}-p\right\|+\frac{c_{n}}{1-d_{n}}\left\|T_{1} x_{n}-p\right\| \\
\leq & \limsup _{n \rightarrow \infty} \frac{a_{n}+b_{n}}{1-d_{n}}\left\|x_{n-1}-p\right\|+\frac{c_{n}}{1-d_{n}}\left\|x_{n}-p\right\| \\
\leq & \limsup _{n \rightarrow \infty} \frac{a_{n}+b_{n}+c_{n}}{1-d_{n}}\left\|x_{n-1}-p\right\|=d .
\end{aligned}
$$

By Lemma 2.3,

$$
\lim _{n \rightarrow \infty}\left\|\frac{a_{n}}{1-d_{n}}\left(x_{n-1}-p\right)+\frac{b_{n}}{1-d_{n}}\left(S x_{n-1}-p\right)+\frac{c_{n}}{1-d_{n}}\left(T_{1} x_{n}-p\right)-\left(T_{2} x_{n}-p\right)\right\|=0 .
$$

This implies that $\lim _{n \rightarrow \infty}|| x_{n}-T_{2} x_{n} \|=0$. Similarly, $\lim _{n \rightarrow \infty}|| x_{n}-T_{1} x_{n} \|=0$.

Since $\left\{x_{n}\right\}$ is bounded, there exists $r>0$ such that $2 \sup \left\{\left\|x_{n}-p\right\|: n \in \mathbb{N}\right\} \leq r$.

By Lemma 2.1, there exists a strictly increasing, continuous, and convex function $g$ : $[0,2 r] \rightarrow[0, \infty)$ such that $g(0)=0$ and

$$
\begin{aligned}
& \left\|x_{n}-p\right\|^{2} \\
\leq & a_{n}\left\|x_{n-1}-p\right\|^{2}+b_{n}\left\|S x_{n-1}-p\right\|^{2}+c_{n}\left\|T_{1} x_{n}-p\right\|^{2}+d_{n}\left\|T_{2} x_{n}-p\right\|^{2} \\
& -a_{n} b_{n} g\left(\left\|x_{n-1}-S x_{n-1}\right\|\right) \\
\leq & \left(a_{n}+b_{n}\right)\left\|x_{n-1}-p\right\|^{2}+\left(c_{n}+d_{n}\right)\left\|x_{n}-p\right\|^{2}-a_{n} b_{n} g\left(\left\|x_{n-1}-S x_{n-1}\right\|\right) .
\end{aligned}
$$


This implies that

$$
a_{n} b_{n} g\left(\left\|x_{n-1}-S x_{n-1}\right\|\right) \leq\left(a_{n}+b_{2}\right)\left(\left\|x_{n-1}-p\right\|^{2}-\left\|x_{n}-p\right\|^{2}\right) .
$$

By the properties of $g$ and $\lim _{n \rightarrow \infty}|| x_{n}-p \|=d$, we get $\lim _{n \rightarrow \infty}|| x_{n}-S x_{n} \|=0$.

Theorem 3.1. Let $E$ be a uniformly convex Banach space with Opial's condition, $C$ be a nonempty closed convex subset of $E$, and let $T_{1}, T_{2}: C \rightarrow C$ be two nonexpansive mappings, and let $S: C \rightarrow C$ be a mapping with condition $(C)$. Let $\left\{a_{n}\right\},\left\{b_{n}\right\},\left\{c_{n}\right\}$, and $\left\{d_{n}\right\}$ be sequences with $0<a \leq a_{n}, b_{n}, c_{n}, d_{n} \leq b<1$ and $a_{n}+b_{n}+c_{n}+d_{n}=1$. Suppose that $\Omega:=F(S) \cap F\left(T_{1}\right) \cap F\left(T_{2}\right) \neq \emptyset$. Define a sequence $\left\{x_{n}\right\}$ by

$$
\left\{\begin{array}{l}
x_{0} \in C \text { chosen arbitrary, } \\
x_{n}=a_{n} x_{n-1}+b_{n} S x_{n-1}+c_{n} T_{1} x_{n}+d_{n} T_{2} x_{n} .
\end{array}\right.
$$

Then, $x_{n} \rightarrow z$ for some $z \in \Omega$.

Proof. By Lemma 3.1, $\left\{x_{n}\right\}$ is a bounded sequence. Then, there exists a subsequence $\left\{x_{n_{k}}\right\}$ of $\left\{x_{n}\right\}$ and $z \in C$ such that $x_{n_{k}} \rightarrow z$. By Lemmas 2.6, 2.7, and 3.1, we know that $z \in \Omega$. Since $E$ has Opial's condition, it is easy to see that $x_{n} \rightarrow z$.

Hence, the proof is completed.

Remark 3.1. The conclusion of Theorem 3.1 is still true if $S: C \rightarrow C$ is a quasi-nonexpansive mapping, and $I-S$ is demiclosed at zero, that is, $x_{n} \rightarrow x$ and $(I-S) x_{n} \rightarrow 0$ implies that $(I-S) x=0$.

In Theorem 3.1, if $S=I$, then we get the following result. Hence, Theorem 3.1 generalizes Theorem 4 in [5].

Corollary 3.1. [5] Let $E$ be a uniformly convex Banach space with Opial's condition, $C$ be a nonempty closed convex subset of $E$, and let $T_{1}, T_{2}: C \rightarrow C$ be two nonexpansive mappings. Let $\left\{a_{n}\right\}$, $\left\{b_{n}\right\}$, and $\left\{c_{n}\right\}$ be sequences with $0<a \leq a_{n}, b_{n}, c_{n} \leq b<1$ and $a_{n}+b_{n}+c_{n}=1$. Suppose that $\Omega:=F\left(T_{1}\right) \cap F\left(T_{2}\right) \neq \emptyset$.

Define a sequence $\left\{x_{n}\right\}$ by

$$
\left\{\begin{array}{l}
x_{0} \in C \text { chosen arbitrary } \\
x_{n}=a_{n} x_{n-1}+b_{n} T_{1} x_{n}+c_{n} T_{2} x_{n}
\end{array}\right.
$$

Then, $x_{n} \rightarrow z$ for some $z \in \Omega$.

Besides, it is easy to get the following result from Theorem 3.1.

Corollary 3.2. Let $E$ be a uniformly convex Banach space with Opial's condition, $C$ be a nonempty closed convex subset of $E$, and let $S: C \rightarrow C$ be a mapping with condition $(C)$. Let $\left\{a_{n}\right\}$ be a sequence with $0<a \leq a_{n} \leq b<1$. Suppose that $F(S) \neq \varnothing$. Define a sequence $\left\{x_{n}\right\}$ by

$$
\left\{\begin{array}{l}
x_{0} \in C \text { chosen arbitrary, } \\
x_{n}=a_{n} x_{n-1}+\left(1-a_{n}\right) S x_{n-1}
\end{array} .\right.
$$

Then, $x_{n} \rightarrow z$ for some $z \in F(S)$.

Proof. Let $T_{1}=T_{2}=I$, where $I$ is the identity mapping. For each $n \in \mathbb{N}$, we know that

$$
x_{n}=\frac{a_{n}}{2} x_{n-1}+\frac{1-a_{n}}{2} S x_{n-1}+\frac{1}{4} T_{1} x_{n}+\frac{1}{4} T_{2} x_{n} .
$$

By Theorem 3.1, it is easy to get the conclusion. 
Theorem 3.2. Let $E$ be a uniformly convex Banach space with Opial's condition, $C$ be a nonempty closed convex subset of $E$, and let $T_{1}, T_{2}: C \rightarrow C$ be two nonexpansive mappings, and let $S: C \rightarrow C$ be a mapping with condition (C). Let $\left\{a_{n}\right\},\left\{b_{n}\right\},\left\{c_{n}\right\}$, and $\left\{d_{n}\right\}$ be sequences with $0<a \leq a_{n}, b_{n}, c_{n}, d_{n} \leq b<1$ and $a_{n}+b_{n}+c_{n}=1$. Suppose that $\Omega:=F(S) \cap F\left(T_{1}\right) \cap F\left(T_{2}\right) \neq \emptyset$. Define a sequence $\left\{x_{n}\right\}$ by

$$
\left\{\begin{array}{l}
x_{0} \in C \text { chosen arbitrary } \\
y_{n}=a_{n} x_{n-1}+b_{n} T_{1} y_{n}+c_{n} T_{2} y_{n} \\
x_{n}=d_{n} y_{n}+\left(1-d_{n}\right) S y_{n} .
\end{array}\right.
$$

Then, $x_{n} \rightarrow z$ for some $z \in \Omega$.

Proof. Following the same argument as in Lemma 3.1, we know that $\left\{y_{n}\right\}$ is welldefined. Take any $w \in \Omega$ and let $w$ be fixed. Then, for each $n \in \mathbb{N}$, we have

$$
\begin{aligned}
\left\|y_{n}-w\right\| & =\left\|a_{n} x_{n-1}+b_{n} T_{1} y_{n}+c_{n} T_{2} y_{n}-w\right\| \\
& \leq a_{n}\left\|x_{n-1}-w\right\|+b_{n}\left\|T_{1} y_{n}-w\right\|+c_{n}\left\|T_{2} y_{n}-w\right\| \\
& \leq a_{n}\left\|x_{n-1}-w\right\|+\left(b_{n}+c_{n}\right)\left\|y_{n}-w\right\| .
\end{aligned}
$$

This implies that $\left\|y_{n}-w\right\| \leq\left\|x_{n-1}-w\right\|$ for each $n \in \mathbb{N}$. Besides, we also have

$$
\begin{aligned}
\left\|x_{n}-w\right\| & =\left\|d_{n} y_{n}+\left(1-d_{n}\right) S y_{n}-w\right\| \\
& \leq d_{n}\left\|y_{n}-w\right\|+\left(1-d_{n}\right)\left\|S y_{n}-w\right\| \\
& \leq\left\|y_{n}-w\right\| .
\end{aligned}
$$

Hence, $\left\|x_{n}-w\right\| \leq\left\|y_{n}-w\right\| \leq\left\|x_{n-1}-w\right\|$ for each $n \in \mathbb{N}$. So, $\lim _{n \rightarrow \infty}\left\|x_{n}-w\right\|$ and $\lim _{n \rightarrow \infty}|| y_{n}-w \|$ exist, and $\left\{x_{n}\right\},\left\{y_{n}\right\}$ are bounded sequences.

Suppose that $\lim _{n \rightarrow \infty}|| x_{n}-w \|=\lim _{n \rightarrow \infty}|| y_{n}-w||=d$. Clearly, $\lim _{\sup _{n \rightarrow \infty}}\left\|T_{2} y_{n}-w\right\| \leq$ $d$, and we have

$$
\begin{aligned}
& \lim _{n \rightarrow \infty}\left\|y_{n}-w\right\| \\
= & \lim _{n \rightarrow \infty}\left\|a_{n} x_{n-1}+b_{n} T_{1} y_{n}+c_{n} T_{2} y_{n}-w\right\| \\
= & \lim _{n \rightarrow \infty}\left\|\left(1-c_{n}\right)\left[\frac{a_{n}}{1-c_{n}}\left(x_{n-1}-w\right)+\frac{b_{n}}{1-c_{n}}\left(T_{1} y_{n}-w\right)\right]+c_{n}\left(T_{2} y_{n}-w\right)\right\| .
\end{aligned}
$$

Besides,

$$
\begin{aligned}
& \limsup _{n \rightarrow \infty}\left\|\frac{a_{n}}{1-c_{n}}\left(x_{n-1}-w\right)+\frac{b_{n}}{1-c_{n}}\left(T_{1} y_{n}-w\right)\right\| \\
\leq & \limsup _{n \rightarrow \infty} \frac{a_{n}}{1-c_{n}}\left\|x_{n-1}-w\right\|+\frac{b_{n}}{1-c_{n}}\left\|T_{1} y_{n}-w\right\| \\
\leq & \limsup _{n \rightarrow \infty} \frac{a_{n}}{1-c_{n}}\left\|x_{n-1}-w\right\|+\frac{b_{n}}{1-c_{n}}\left\|y_{n}-w\right\| \\
\leq & \limsup _{n \rightarrow \infty}\left\|x_{n-1}-w\right\|=d .
\end{aligned}
$$

By Lemma 2.3,

$$
\lim _{n \rightarrow \infty}\left\|\frac{a_{n}}{1-c_{n}}\left(x_{n-1}-w\right)+\frac{b_{n}}{1-c_{n}}\left(T_{1} y_{n}-w\right)-\left(T_{2} y_{n}-w\right)\right\|=0 .
$$

This implies that $\lim _{n \rightarrow \infty}|| y_{n}-T_{2} y_{n} \|=0$. Similarly, $\lim _{n \rightarrow \infty}\left\|y_{n}-T_{1} y_{n}\right\|=0$. 
Since $\left\{x_{n}\right\}$ and $\left\{y_{n}\right\}$ are bounded sequences, there exists $r>0$ such that

$$
2 \sup \left\{\left\|x_{n}\right\|,\left\|y_{n}\right\|,\left\|x_{n}-w\right\|,\left\|y_{n}-w\right\|: n \in \mathbb{N}\right\} \leq r .
$$

By Lemma 2.1, there exists a strictly increasing, continuous, and convex function $g$ : $[0,2 r] \rightarrow[0, \infty)$ such that $g(0)=0$ and

$$
\left\|d_{n} y_{n}+\left(1-d_{n}\right) S y_{n}-w\right\|^{2} \leq d_{n}\left\|y_{n}-w\right\|^{2}+\left(1-d_{n}\right)\left\|S y_{n}-w\right\|^{2}-d_{n}\left(1-d_{n}\right) g\left(\left\|y_{n}-S y_{n}\right\|\right) .
$$

This implies that

$$
d_{n}\left(1-d_{n}\right) g\left(\left\|y_{n}-S y_{n}\right\|\right) \leq\left\|y_{n}-w\right\|^{2}-\left\|x_{n}-w\right\|^{2}
$$

Since $\lim _{n \rightarrow \infty}|| x_{n}-w\left\|=\lim _{n \rightarrow \infty}|| y_{n}-w\right\|=d$, and the properties of $g$, we get $\lim _{n \rightarrow \infty}\left\|y_{n}-S y_{n}\right\|=0$. Besides,

$$
\left\|x_{n}-y_{n}\right\|=\left\|d_{n} y_{n}+\left(1-d_{n}\right) S y_{n}-y_{n}\right\|=\left(1-d_{n}\right)\left\|y_{n}-S y_{n}\right\|
$$

Hence, $\lim _{n \rightarrow \infty}|| x_{n}-y_{n} \|=0$. Finally, following the same argument as in the proof of Theorem 3.1, we know that $x_{n} \rightarrow z$ for some $z \in \Omega$.

Next, we give the following examples for Theorems 3.1 and 3.2.

Example 3.1. Let $E=\mathbb{R}, C:=[0,3], T_{1} x=T_{2} x=x$, and let $S: C \rightarrow C$ be the same as in [1]:

$$
S x:=\left\{\begin{array}{l}
0 \text { if } x \neq 3 \\
1 \text { if } x=3
\end{array}\right.
$$

For each $n$, let $a_{n}=b_{n}=c_{n}=d_{n}=\frac{1}{4}$. Let $x_{0}=1$. Then, for the sequence $\left\{x_{n}\right\}$, in Theorem 3.1, we know that $x_{n}=\frac{1}{2^{n}}$ for all $n \in \mathbb{N}$, and $x_{n} \rightarrow 0$, and 0 is a common fixed point of $S, T_{1}$, and $T_{2}$.

Example 3.2. Let $E, C, T_{1}, T_{2}, S$ be the same as in Example 3.1. For each $n$, let $a_{n}=b_{n}=c_{n}=\frac{1}{3}$, and $d_{n}=\frac{1}{2}$. Let $x_{0}=1$. Then, for the sequence $\left\{x_{n}\right\}$ in Theorem 3.1, we know that $x_{n}=\frac{1}{2^{n}}$ for all $n \in \mathbb{N}$, and $x_{n} \rightarrow 0$, and 0 is a common fixed point of $S$, $T_{1}$, and $T_{2}$.

Example 3.3. Let $E, C,\left\{a_{n}\right\},\left\{b_{n}\right\},\left\{c_{n}\right\},\left\{d_{n}\right\}$, and let $S: C \rightarrow C$ be the same as in Example 3.1. Let $T_{1} x=T_{2} x=0$ for each $x \in C$. Then, for the sequence $\left\{x_{n}\right\}$ in Theorem 3.1, we know that $x_{n}=\frac{1}{4^{n}}$ for all $n \in \mathbb{N}$.

Example 3.4. Let $E, C,\left\{a_{n}\right\},\left\{b_{n}\right\},\left\{c_{n}\right\},\left\{d_{n}\right\}$, and let $S: C \rightarrow C$ be the same as in Example 3.2. Let $T_{1} x=T_{2} x=0$ for each $x \in C$. Then, for the sequence $\left\{x_{n}\right\}$ in Theorem 3.2, we know that $x_{n}=\frac{1}{6^{n}}$ for all $n \in \mathbb{N}$.

\section{Remark 3.2.}

(i) For the rate of convergence, by Examples 3.3 and 3.4, we know that the iteration process in Theorem 3.2 may be faster than the iteration process in Theorem 3.1. 
But, the times of iteration process for Theorem 3.2 is much than ones in Theorem 3.1.

(ii) The conclusion of Theorem 3.2 is still true if $S: C \rightarrow C$ is a quasi-nonexpansive mapping, and $I-S$ is demiclosed at zero, that is, $x_{n} \rightarrow x$ and $(I-S) x_{n} \rightarrow 0$ implies that $(I-S) x=0$.

(iii) Corollaries 3.1 and 3.2 are special cases of Theorem 3.2.

Definition 3.1. [18] Let $C$ be a nonempty subset of a Banach space $E$. A mapping $T$ : $C \rightarrow E$ satisfy condition $(E)$ if there exists $\mu \geq 1$ such that for all $x, y \in C$,

$$
\|x-T y\| \leq \mu\|x-T x\|+\|x-y\| .
$$

By Lemma 7 in [1], we know that if $T$ satisfies condition $(C)$, then $T$ satisfies condition $(E)$. But, the converse may be false [18, Example 1]. Furthermore, we also observe the following result.

Lemma 3.2. [18] Let $C$ be a nonempty subset of a Banach space $E$. Let $T: C \rightarrow E$ be a mapping. Assume that:

(i) $\lim _{n \rightarrow \infty}\left\|x_{n}-T x_{n}\right\|=0$ and $x_{n}-x$;

(ii) $T$ satisfies condition $(E)$;

(iii) $E$ has Opial condition.

Then, $T x=x$.

By Lemma 3.2, if $S$ satisfies condition $(E)$, then the conclusions of Theorems 3.1 and 3.2 are still true. Hence, we can use the following condition to replace condition $(C)$ in Theorems 3.1 and 3.2 by Proposition 19 in [19].

Definition 3.2. [19] Let $T$ be a mapping on a subset $C$ of a Banach space $E$. Then, $T$ is said to satisfy (SKC)-condition if

$$
\frac{1}{2}\|x-T x\| \leq\|x-y\| \Rightarrow\|T x-T y\| \leq N(x, y),
$$

where $N(x, y):=\max \left\{\|x-y\|, \frac{1}{2}(\|x-T x\|+\|T y-y\|), \frac{1}{2}(\|T x-y\|+\|x-T y\|)\right\}$ for all $x, y \in C$.

\section{Strong convergence theorems (I)}

Let $C$ be a nonempty closed convex subset of a Banach space $E$. A point $p$ in $C$ is said to be an asymptotic fixed point of a mapping $T: C \rightarrow C$ if $C$ contains a sequence $\left\{x_{n}\right\}$ which converges weakly to $p$ such that $\lim _{n \rightarrow \infty},|| x_{n}-T x_{n} \|=0$. The set of asymptotic fixed points of $T$ will be denoted by $\hat{F}(T)$. A mapping $T: C \rightarrow C$ is called relatively nonexpansive [20] if $F(T) \neq 0, \hat{F}(T)=F(T)$, and $\varphi(p, T x) \leq \varphi(p, x)$ for all $x \in C$ and $p \in$ $F(T)$. Note that every identity mapping is a relatively nonexpansive mapping.

Lemma 4.1. [21] Let $E$ be a strictly convex and smooth Banach space, let $C$ be a closed convex subset of $E$, and let $T: C \rightarrow C$ be a relatively nonexpansive mapping. Then, $F(T)$ is a closed and convex subset of $C$.

The following property is motivated by the property $\left(Q_{4}\right)$ in [22]. 
Definition 4.1. Let $E$ be a Banach space. Then, we say that $E$ satisfies condition (Q) if for each $x, y, z_{1}, z_{2} \in E$ and $t \in[0,1]$,

$$
\left\|x-z_{i}\right\| \leq\left\|y-z_{i}\right\|, i=1,2 \Rightarrow \| x-\left(t z_{1}+(1-t) z_{2}\|\leq\| y-\left(t z_{1}+(1-t) z_{2}\right) \| .\right.
$$

Remark 4.1. If $H$ is a Hilbert space, then $H$ satisfies condition $(Q)$.

Theorem 4.1. Let $E$ be a uniformly convex and uniformly smooth Banach space with condition $(Q)$, and let $C$ be a nonempty closed convex subset of $E$, and let $T_{1}, T_{2}: C$ $\rightarrow C$ be two nonexpansive mappings, and let $S: C \rightarrow C$ be a relatively nonexpansive mapping. Let $\left\{a_{n}\right\},\left\{b_{n}\right\},\left\{c_{n}\right\}$, and $\left\{d_{n}\right\}$ be sequences in $(0,1)$ with and $a_{n}+b_{n}+c_{n}=1$. Suppose that $\Omega:=F(S) \cap F\left(T_{1}\right) \cap F\left(T_{2}\right) \neq \emptyset$. Define a sequence $\left\{x_{n}\right\}$ by

$$
\left\{\begin{array}{l}
x_{0} \in C \text { chosen arbitrary and } C_{0}=D_{0}=C, \\
y_{n}=a_{n} x_{n-1}+b_{n} T_{1} y_{n}+c_{n} T_{2} y_{n} \\
z_{n}=J^{-1}\left(d_{n} J y_{n}+\left(1-d_{n}\right) J S y_{n}\right) \\
C_{n}=\left\{z \in C_{n-1}: \phi\left(z, z_{n}\right) \leq \phi\left(z, y_{n}\right)\right\} \\
D_{n}=\left\{z \in D_{n-1}:\left\|y_{n}-z\right\| \leq\left\|x_{n-1}-z\right\|\right\} \\
x_{n}=\Pi_{C_{n} \cap D_{n} x_{0}} .
\end{array}\right.
$$

Assume that $\lim \inf _{n \rightarrow \infty} b_{n}>0, \lim _{\inf _{n \rightarrow \infty}} c_{n}>0$, and $\lim _{\inf _{n \rightarrow \infty}} d_{n}\left(1-d_{n}\right)>0$.

Then, $\lim _{n \rightarrow \infty} x_{n}=\lim _{n \rightarrow \infty} y_{n}=\lim _{n \rightarrow \infty} z_{n}=\prod_{\Omega} x_{0}$.

Proof. Following the same argument as in Lemma 3.1, we know that $\left\{y_{n}\right\}$ is welldefined.

Clearly, $C_{0}$ and $D_{0}$ are nonempty closed convex subsets of $C$, and $C_{n}$ is a closed subset of $C$ for every $n \in \mathbb{N}$. Since $\varphi\left(z, z_{n}\right) \leq \varphi\left(z, y_{n}\right)$ is equivalent to

$$
2\left\langle z_{1} J y_{n}-J z_{n}\right\rangle \leq\left\|y_{n}\right\|^{2}-\left\|z_{n}\right\|^{2},
$$

it is easy to see that $C_{n}$ is a convex set for each $n \in \mathbb{N}$. Besides, by condition $(Q)$, it is easy to see that $D_{n}$ is a nonempty closed convex subset of $C$.

Next, we want to show that $\Omega \subseteq C_{n} \cap D_{n}$ for each $n \in \mathbb{N} \cup\{0\}$. Clearly, $\Omega \subseteq C_{0}$. Suppose that $\Omega \subseteq C_{n-1}$. Let $w \in \Omega$. Then, $w \in F(S)$ and

$$
\begin{aligned}
\phi\left(w, z_{n}\right) & =\phi\left(w, J^{-1}\left(d_{n} J y_{n}+\left(1-d_{n}\right) J S y_{n}\right)\right) \\
& \leq d_{n} \phi\left(w, y_{n}\right)+\left(1-d_{n}\right) \phi\left(w, S y_{n}\right) \\
& \leq d_{n} \phi\left(w, y_{n}\right)+\left(1-d_{n}\right) \phi\left(w, y_{n}\right)=\phi\left(w, y_{n}\right) .
\end{aligned}
$$

So, $\Omega \subseteq C_{n}$. By induction, $\Omega \subseteq C_{n}$ for each $n \in \mathbb{N} \cup\{0\}$.

Clearly, $\Omega \subseteq D_{0}$. Suppose that $\Omega \subseteq D_{n-1}$. Let $w \in \Omega$. Then, $w \in F\left(T_{1}\right) \cap F\left(T_{2}\right)$ and

$$
\begin{aligned}
\left\|y_{n}-w\right\| & \leq a_{n}\left\|x_{n-1}-w\right\|+b_{n}\left\|T_{1} y_{n}-w\right\|+c_{n}\left\|T_{2} y_{n}-w\right\| \\
& \leq a_{n}\left\|x_{n-1}-w\right\|+b_{n}\left\|y_{n}-w\right\|+c_{n}\left\|y_{n}-w\right\| .
\end{aligned}
$$

This implies that $\left\|y_{n}-w\right\| \leq\left\|x_{n-1}-w\right\|$ and $w \in D_{n}$. By induction, $\Omega \subseteq D_{n}$ for each $n \in \mathbb{N} \cup\{0\}$. So, $\Omega \subseteq C_{n} \cap D_{n}$ for each $n \in \mathbb{N} \cup\{0\}$.

Since $x_{n}=\Pi_{C_{n} \cap D_{n} x_{0}}$,

$$
\phi\left(x_{n}, x_{0}\right) \leq \phi\left(w, x_{0}\right)-\phi\left(w, x_{n}\right) \leq \phi\left(w, x_{0}\right)
$$

for each $w \in \Omega$. Therefore, $\left\{\varphi\left(x_{n}, x_{0}\right)\right\}$ is a bounded sequence. Furthermore, $\left\{x_{n}\right\}$ is a bounded sequence. 
By Lemma 2.5, $x_{n}=\Pi_{C_{n} \cap D_{n} x_{0}}$, and $x_{n+1}=\Pi_{C_{n+1} \cap D_{n+1}} x_{0}$,

$$
\phi\left(x_{n+1}, x_{n}\right)=\phi\left(x_{n+1}, \Pi_{C_{n} \cap D_{n}} x_{0}\right) \leq \phi\left(x_{n+1}, x_{0}\right)-\phi\left(x_{n}, x_{0}\right) .
$$

Hence, $\varphi\left(x_{n}, x_{0}\right) \leq \varphi\left(x_{n+1}, x_{0}\right), \lim _{n \rightarrow \infty} \varphi\left(x_{n}, x_{0}\right)$ exists, and $\lim _{n \rightarrow \infty} \varphi\left(x_{n+1}, x_{n}\right)=0$. By Lemma 2.4, $\lim _{n \rightarrow \infty},\left\|x_{n+1}-x_{n}\right\|=0$. Since $x_{n} \in D_{n}$, we know that $\left\|y_{n}-x_{n}\right\| \leq \| x_{n-1^{-}}$ $x_{n} \|$ and $\lim _{n \rightarrow \infty}|| x_{n}-y_{n} \|=0$. Furthermore, $\lim _{n \rightarrow \infty} \varphi\left(x_{n}, y_{n}\right)=0$. Since $x_{n} \in C_{n}$, it is easy to see that $\lim _{n \rightarrow \infty} \varphi\left(x_{n}, z_{n}\right)=0$. Hence, $\lim _{n \rightarrow \infty}|| x_{n}-z_{n} \|=0$.

Take any $w \in \Omega$ and let $w$ be fixed. Let $r:=2 \sup \left\{|| x_{n}||,|| x_{n^{-}} w\|,\| y_{n}||,\left\|y_{n}-w\right\|: n\right.$ $\in \mathbb{N}\}$. By Lemma 2.1, there exists a strictly increasing, continuous, and convex function $g:[0,2 r] \rightarrow[0, \infty)$ such that $g(0)=0$ and

$$
\begin{aligned}
& \left\|y_{n}-w\right\|^{2} \\
\leq & a_{n}|| x_{n-1}-w\left\|^{2}+b_{n}\right\| T_{1} y_{n}-w\left\|^{2}+c_{n}\right\| T_{2} y_{n}-w \|^{2}-a_{n} b_{n} g\left(\left\|x_{n-1}-T_{1} y_{n}\right\|\right) \\
\leq & a_{n}\left\|x_{n-1}-w\right\|^{2}+b_{n}\left\|y_{n}-w\right\|^{2}+c_{n}\left\|y_{n}-w\right\|^{2}-a_{n} b_{n} g\left(\left\|x_{n-1}-T_{1} y_{n}\right\|\right) .
\end{aligned}
$$

This implies that

$$
b_{n} g\left(\left\|x_{n-1}-T_{1} y_{n}\right\|\right) \leq\left\|x_{n-1}-y_{n}\right\|\left(\left\|x_{n-1}-w\right\|+\left\|y_{n}-w\right\|\right) .
$$

So, $\lim _{n \rightarrow \infty} b_{n} g\left(\left\|x_{n-1}-T_{1} y_{n}\right\|\right)=0$. By (ii), $\lim _{n \rightarrow \infty}|| x_{n-1}-T_{1} y_{n} \|=0$. Furthermore, $\lim _{n \rightarrow \infty}|| y_{n}-T_{1} y_{n} \|=0$. Similarly, $\lim _{n \rightarrow \infty}|| y_{n}-T_{2} y_{n} \|=0$.

By Lemma 2.2, there exists a strictly increasing, continuous, and convex function $g$ ': $[0,2 r] \rightarrow[0, \infty)$ such that $g^{\prime}(0)=0$ and

$$
\begin{aligned}
\phi\left(w, z_{n}\right) & \leq d_{n} \phi\left(w, y_{n}\right)+\left(1-d_{n}\right) \phi\left(w, S y_{n}\right)-d_{n}\left(1-d_{n}\right) g^{\prime}\left(\left\|J y_{n}-J S y_{n}\right\|\right) \\
& \leq \phi\left(w, y_{n}\right)-d_{n}\left(1-d_{n}\right) g^{\prime}\left(\left\|J y_{n}-J S y_{n}\right\|\right) .
\end{aligned}
$$

Hence,

$$
\begin{aligned}
& d_{n}\left(1-d_{n}\right) g^{\prime}\left(\left\|J y_{n}-J S y_{n}\right\|\right) \\
\leq & \phi\left(w, y_{n}\right)-\phi\left(w, z_{n}\right) \\
= & \left(\|w\|^{2}+\left\|y_{n}\right\|^{2}-2\left\langle w, J y_{n}\right\rangle\right)-\left(\|w\|^{2}+\left\|z_{n}\right\|^{2}-2\left\langle w_{,} J z_{n}\right\rangle\right) \\
= & \left\|y_{n}\right\|^{2}-\left\|z_{n}\right\|^{2}+2\left\langle w, J z_{n}-J y_{n}\right\rangle \\
= & \left\|y_{n}-z_{n}\right\|\left(\left\|y_{n}\right\|+\left\|z_{n}\right\|\right)+2\|w\| \cdot\left\|J z_{n}-J y_{n}\right\| .
\end{aligned}
$$

By Remark 2.1, $\lim _{n \rightarrow \infty} d_{n}\left(1-d_{n}\right) g\left(|| J y_{n}-J S y_{n}||\right)=0$. By assumptions and the properties of $g, \lim _{n \rightarrow \infty}|| J y_{n}-J S y_{n} \|=0$. Furthermore, $\lim _{n \rightarrow \infty}|| y_{n}-S y_{n} \|=0$.

Since $\left\{y_{n}\right\}$ is a bounded sequence, there exists a subsequence $\left\{y_{n_{k}}\right\}$ of $\left\{y_{n}\right\}$ and $\bar{x} \in C$ such that $y_{n_{k}} \rightarrow \bar{x}$. By Lemma 2.6, $\bar{x} \in F\left(T_{1}\right) \cap F\left(T_{2}\right)$. Besides, since $S$ is a relatively nonexpansive mapping, $\bar{x} \in \hat{F}(S)=F(S)$. So, $\bar{x} \in \Omega$.

Finally, we want to show that $y_{n} \rightarrow \Pi_{\Omega} x_{0}$. Let $q=\Pi_{\Omega} x_{0}$. Then, $q \in \Omega \subseteq C_{n} \cap D_{n}$ for each $n \in \mathbb{N}$. So,

$$
\phi\left(x_{n}, x_{0}\right)=\min _{y \in C_{n} \cap D_{n}} \phi\left(y, x_{0}\right) \leq \phi\left(q, x_{0}\right) .
$$

On the other hand, from weakly lower semicontinuity of the norm and $\lim _{n \rightarrow \infty} \| x_{n^{-}}$ $y_{n} \|=0$, we have 


$$
\begin{aligned}
\phi\left(\bar{x}, x_{0}\right) & =\|\bar{x}\|^{2}-2\left\langle\bar{x}, J x_{0}\right\rangle+\left\|x_{0}\right\|^{2} \\
& \leq \liminf _{n \rightarrow \infty}\left(\left\|y_{n_{k}}\right\|^{2}-2\left\langle y_{n_{k}}, J x_{0}\right\rangle+\left\|x_{0}\right\|^{2}\right) \\
& =\liminf _{n \rightarrow \infty}\left(\left\|x_{n_{k}}\right\|^{2}-2\left\langle x_{n_{k}} J x_{0}\right\rangle+\left\|x_{0}\right\|^{2}\right) \\
& \leq \liminf _{n \rightarrow \infty} \phi\left(x_{n_{k}}, x_{0}\right) \\
& \leq \limsup _{n \rightarrow \infty} \phi\left(x_{n_{k}}, x_{0}\right) \leq \phi\left(q, x_{0}\right) .
\end{aligned}
$$

Since $q=\Pi_{\Omega} x_{0}, \bar{x}=q$. Hence, $\lim _{n \rightarrow \infty} \phi\left(x_{n_{k}}, x_{0}\right)=\phi\left(\bar{x}, x_{0}\right)$. So, we have $\lim _{n \rightarrow \infty}\left\|x_{n_{k}}\right\|=\|\bar{x}\|$. Using the Kadec-Klee property of $E$, we obtain that $\lim _{k \rightarrow \infty} x_{n_{k}}=q=\Pi_{\Omega} x_{0}$.

Furthermore, for each weakly convergence subsequence $\left\{x_{n_{m}}\right\}$ of $\left\{x_{n}\right\}$, we know that $\lim _{m \rightarrow \infty} x_{n_{m}}=q=\Pi_{\Omega} y_{1}$ by following the same argument as the above conclusion. Therefore,

$$
\lim _{n \rightarrow \infty} x_{n}=\lim _{n \rightarrow \infty} y_{n}=\lim _{n \rightarrow \infty} z_{n}=\Pi_{\Omega} x_{0}
$$

Hence, the proof is completed.

Remark 4.2. Since nonspreading mappings with fixed points in a strictly convex Banach space with a uniformly Gateaux differentiable norm are relatively nonex-pansive mappings [[23], Theorem 3.3], we know that the conclusion of Theorem 4.1 is still true if $S$ is replaced by a nonspreading mapping.

Next, we give an easy example for Theorem 4.1.

Example 4.1. Let $E=\mathbb{R}, C:=[0,3], T_{1} x=T_{2} x=x$, and let $S: C \rightarrow C$ be the as in [1]:

$$
S x:=\left\{\begin{array}{l}
0 \text { if } x \neq 3 \\
1 \text { if } x=3
\end{array}\right.
$$

For each $n$, let $a_{n}=b_{n}=c_{n}=\frac{1}{3}$ and $d_{n}=\frac{1}{2}$. Let $x_{0}=1$. Hence, we have

(a) $y_{n}=x_{n-1}$ for each $n \in \mathbb{N}$;

(b) $z_{n}=\frac{1}{2} y_{n}$ for each $n \in \mathbb{N}$;

(c) $C_{n}:=\left\{z \in C_{n-1}:\left|z-z_{n}\right| \leq\left|z-y_{n}\right|\right\}=0\left[0, \frac{y_{n}+z n}{2}\right]$;

(d) $D_{n}:=\left\{z \in D_{n-1}:\left|z-y_{n}\right| \leq\left|z-x_{n-1}\right|\right\}=[0,3]$;

(e) $x_{n}=\frac{1}{2}\left(y_{n}+z_{n}\right)=\frac{1}{2}\left(x_{n-1}+\frac{1}{2} x_{n-1}\right)=\frac{3}{4} x_{n-1}$.

By (e) and $x_{0}=1$, we know that $x_{n}=\left(\frac{3}{4}\right)^{n}$ for each $n \in \mathbb{N} \cup\{0\}, \lim _{n \rightarrow \infty} x_{n}=0$, and 0 is a common fixed point of $S, T_{1}$, and $T_{2}$.

The following results are special cases of Theorem 4.1.

Corollary 4.1. Let $E$ be a uniformly convex and uniformly smooth Banach space with condition $(Q)$, and let $C$ be a nonempty closed convex subset of $E$, and let $T_{1}, T_{2}: C$ $\rightarrow C$ be two nonexpansive mappings. Let $\left\{a_{n}\right\},\left\{b_{n}\right\},\left\{c_{n}\right\}$ be sequences in $(0,1)$ with and $a_{n}+b_{n}+c_{n}=1$. Suppose that $\Omega:=F\left(T_{1}\right) \cap F\left(T_{2}\right) \neq \emptyset$. Define a sequence $\left\{x_{n}\right\}$ by 


$$
\left\{\begin{array}{l}
x_{0} \in C \text { chosen arbitrary and } D_{0}=C \\
y_{n}=a_{n} x_{n-1}+b_{n} T_{1} y_{n}+c_{n} T_{2} y_{n} \\
D_{n}=\left\{z \in D_{n-1}:\left\|y_{n}-z\right\| \leq\left\|x_{n-1}-z\right\|\right\} \\
x_{n}=\Pi_{D_{n}} x_{0} .
\end{array}\right.
$$

Assume that $\lim \inf _{n \rightarrow \infty} b_{n}>0, \lim _{\inf _{n \rightarrow \infty}} c_{n}>0$. Then, $\lim _{n \rightarrow \infty} x_{n}=\lim _{n \rightarrow \infty}, y_{n}=$ $\prod_{\Omega} x_{0}$

Corollary 4.2. Let $E$ be a uniformly convex and uniformly smooth Banach space, and let $C$ be a nonempty closed convex subset of $E$, and let $S: C \rightarrow C$ be a relatively nonexpansive mapping. Let $\left\{d_{n}\right\}$ be a sequence in $(0,1)$. Suppose that $F(S) \neq \emptyset$. Define a sequence $\left\{x_{n}\right\}$ by

$$
\left\{\begin{array}{l}
x_{0} \in C \text { chosen arbitrary and } C_{0}=C, \\
z_{n}=J^{-1}\left(d_{n} J x_{n-1}+\left(1-d_{n}\right) J S x_{n-1}\right), \\
C_{n}=\left\{z \in C_{n-1}: \phi\left(z, z_{n}\right) \leq \phi\left(z, x_{n-1}\right)\right\} \\
x_{n}=\Pi_{C_{n}} x_{0} .
\end{array}\right.
$$

Assume that $\lim \inf _{n \rightarrow \infty} d_{n}\left(1-d_{n}\right)>0$. Then, $\lim _{n \rightarrow \infty} x_{n}=\lim _{n \rightarrow \infty} z_{n}=\Pi_{F(s)} x_{0}$.

Remark 4.3. Corollary 4.2 is a generalization of Theorem 4.1 in [24]. But, it is a special case of Theorem 3.1 in [25].

\section{Strong convergence theorems (II)}

In this section, we need the following important lemmas.

Lemma 5.1. [26] Let $E$ be a reflexive Banach space and $f: E \rightarrow \mathbb{R} \cup\{+\infty\}$ be a convex and lower semicontinuous function. Let $C$ be a nonempty bounded and closed convex subset of $E$. Then, the function $f$ attains its minimum on $C$. That is, there exists $x^{*} \in$ $C$ such that $f\left(x^{*}\right) \leq f(x)$ for all $x \in C$.

Lemma 5.2. In a Banach space $E$, there holds the inequality

$$
\|x+y\|^{2} \leq\|x\|^{2}+2\langle y, j(x+y)\rangle, \quad x, y \in E,
$$

where $j(x+y) \in J(x+y)$.

Lemma 5.3. [27] Let $C$ be a nonempty closed convex subset of a Banach space $E$ with a uniformly Gâteaux differentiable norm. Let $\left\{x_{n}\right\}$ be a bounded sequence of $E$ and let $\mu_{n}$ be a Banach limit and $z \in C$. Then,

$$
\mu_{n}\left\|x_{n}-z\right\|^{2}=\min _{y \in C} \mu_{n}|| x_{n}-y \|^{2} \Leftrightarrow \mu_{n}\left\langle y-z_{\prime} J\left(x_{n}-z\right)\right\rangle \leq 0 \text { for all } y \in C .
$$

Lemma 5.4. [28] Let $\alpha$ be a real number and $\left(x_{0}, x_{1}, \ldots\right) \in \ell^{2}$ such that $\mu_{n} x_{n} \leq \alpha$ for all Banach $\mu_{n}$. If $\lim \sup _{n \rightarrow \infty}\left(x_{n+1}-x_{n}\right) \leq 0$, then $\lim \sup _{n \rightarrow \infty} x_{n} \leq \alpha$.

Lemma 5.5. [29] Assume that $\left\{a_{n}\right\}_{n \in \mathbb{N}}$ is a sequence of nonnegative real numbers such that $a_{n+1}<\left(1-\gamma_{n}\right) a_{n}+\delta_{n}, n \in \mathbb{N}$, where $\left\{\gamma_{n}\right\} \subseteq(0,1)$ and $\delta_{n}$ is a sequence in $\mathbb{R}$ such that (i) $\sum_{n=1}^{\infty} \gamma_{n}=\infty$; (ii) $\lim \sup _{n \rightarrow \infty} \frac{\delta n}{\gamma n} \leq 0$ or $\sum_{n=1}^{\infty}\left|\delta_{n}\right|<\infty$. Then, $\lim _{n \rightarrow \infty}$ $a_{n}=0$.

Theorem 5.1. Let $E$ be a uniformly convex and uniformly smooth Banach space with Opial's condition, $C$ be a nonempty closed convex subset of $E$, and let $T_{1}, T_{2}: C \rightarrow C$ be two nonexpansive mappings, and let $S: C \rightarrow C$ be a mapping with condition $(C)$. Let $\left\{a_{n}\right\},\left\{b_{n}\right\}$, and $\left\{c_{n}\right\}$ be sequences in $(a, b)$ for some $0<a, b<1$ with $a_{n}+b_{n}+c_{n}=$ 
1. Let $\left\{d_{n}\right\}$ be a sequence in $[0,1]$. Suppose that $\Omega:=F(S) \cap F\left(T_{1}\right) \cap F\left(T_{2}\right) \neq \emptyset$. Define a sequence $\left\{x_{n}\right\}$ by

$$
\left\{\begin{array}{l}
x_{0} \in C \text { chosen arbitrary, } \\
y_{n}=a_{n} x_{n-1}+b_{n} T_{1} y_{n}+c_{n} T_{2} y_{n} \\
x_{n}=d_{n} x_{0}+\left(1-d_{n}\right) S y_{n} .
\end{array}\right.
$$

Assume that:

(i) $\lim _{n \rightarrow \infty} d_{n}=0, \sum_{n=1}^{\infty} d_{n}=\infty$, and $\lim _{n \rightarrow \infty} \frac{\left|d_{n+1}-d_{n}\right|}{d_{n}}=0$;

(ii) $\lim _{n \rightarrow \infty}\left(a_{n+1}-a_{n}\right)=\lim _{n \rightarrow \infty}\left(b_{n+1}-b_{n}\right)=\lim _{n \rightarrow \infty}\left(c_{n+1}-c_{n}\right)=0$.

Then, $\lim _{n \rightarrow \infty} x_{n}=\lim _{n \rightarrow \infty} y_{n}=\bar{x}$ for some $\bar{x} \in \Omega$.

Proof. Following the same argument as in Lemma 3.1, we know that $\left\{y_{n}\right\}$ is welldefined. Take any $w \in \Omega:=F(S) \cap F\left(T_{1}\right) \cap F\left(T_{2}\right)$ and let $w$ be fixed. Then, for each $n$ $\in \mathbb{N}$, we have

$$
\begin{aligned}
& \left\|y_{n}-w\right\| \\
\leq & a_{n}\left\|x_{n-1}-w\right\|+b_{n}\left\|T_{1} y_{n}-w\right\|+c_{n}\left\|T_{2} y_{n}-w\right\| \\
\leq & a_{n}\left\|x_{n-1}-w\right\|+\left(b_{n}+c_{n}\right)\left\|y_{n}-w\right\| .
\end{aligned}
$$

This implies that $\left\|y_{n}-w\right\| \leq\left\|x_{n-1}-w\right\|$ for each $n \in \mathbb{N}$. Next, we have

$$
\begin{aligned}
& \left\|x_{n}-w\right\| \\
\leq & d_{n}\left\|x_{0}-w\right\|+\left(1-d_{n}\right)\left\|S y_{n}-w\right\| \\
\leq & d_{n}\left\|x_{0}-w\right\|+\left(1-d_{n}\right)\left\|y_{n}-w\right\| \\
\leq & d_{n}\left\|x_{0}-w\right\|+\left(1-d_{n}\right)\left\|x_{n-1}-w\right\| \\
& \vdots \\
\leq & \max \left\{\left\|x_{0}-w\right\|,\left\|x_{1}-w\right\|\right\} .
\end{aligned}
$$

Then, $\left\{x_{n}\right\}$ is a bounded sequence. Furthermore, $\left\{y_{n}\right\},\left\{S y_{n}\right\},\left\{T_{1} y_{n}\right\},\left\{T_{2} y_{n}\right\}$ are bounded sequences. Define $M$ as

$$
M:=\sup \left\{\left\|x_{n}\right\|,\left\|y_{n}\right\|,\left\|T_{1} y_{n}\right\|,\left\|T_{2} y_{n}\right\|,\left\|S y_{n}\right\|,\left\|x_{n}-w\right\|,\left\|y_{n}-w\right\|: n \in \mathbb{N}\right\} .
$$

Besides, we know that

$$
\begin{aligned}
& \limsup _{n \rightarrow \infty}\left\|x_{n}-w\right\| \\
\leq & \limsup _{n \rightarrow \infty}\left(d_{n}\left\|x_{0}-w\right\|+\left(1-d_{n}\right)\left\|y_{n}-w\right\|\right) \\
\leq & \limsup _{n \rightarrow \infty} d_{n}\left\|x_{0}-w\right\|+\limsup _{n \rightarrow \infty}\left\|y_{n}-w\right\| \\
\leq & \limsup _{n \leftarrow \infty}\left\|x_{n-1}-w\right\| .
\end{aligned}
$$

This implies that

$$
\limsup _{n \rightarrow \infty}\left\|x_{n}-w\right\|=\limsup _{n \rightarrow \infty}\left\|y_{n}-w\right\| .
$$


By Lemma 2.1, there exists a strictly increasing, continuous, and convex function $g$ : $[0,2 M] \rightarrow \mathbb{R}$ such that

$$
\begin{aligned}
& \left\|y_{n}-w\right\|^{2} \\
\leq & a_{n}\left\|x_{n-1}-w\right\|^{2}+b_{n}\left\|T_{1} y_{n}-w\right\|^{2}+c_{n}\left\|T_{2} y_{n}-w\right\|^{2}-a_{n} b_{n}\left\|x_{n-1}-T_{1} y_{n}\right\|^{2} \\
\leq & a_{n}\left\|x_{n-1}-w\right\|^{2}+b_{n}\left\|y_{n}-w\right\|^{2}+c_{n}\left\|y_{n}-w\right\|^{2}-a_{n} b_{n}\left\|x_{n-1}-T_{1} y_{n}\right\|^{2} .
\end{aligned}
$$

Then,

$$
\begin{aligned}
& \left\|y_{n}-w\right\|^{2} \\
\leq & \left\|y_{n}-w\right\|^{2}+a\left\|x_{n-1}-T_{1} y_{n}\right\|^{2} \\
\leq & \left\|y_{n}-w\right\|^{2}+b_{n}\left\|x_{n-1}-T_{1} y_{n}\right\|^{2} \\
\leq & \left\|x_{n-1}-w\right\|^{2} .
\end{aligned}
$$

This implies that

$$
\lim _{n \rightarrow \infty}\left\|x_{n-1}-T_{1} y_{n}\right\|=0 .
$$

Similar, we have

$$
\lim _{n \rightarrow \infty}\left\|x_{n-1}-T_{2} y_{n}\right\|=0 .
$$

By (i),

$$
\lim _{n \rightarrow \infty}\left\|x_{n}-S y_{n}\right\|=\lim _{n \rightarrow \infty} d_{n}\left\|x_{0}-S y_{n}\right\|=0
$$

and

$$
\begin{aligned}
& \left\|x_{n+1}-x_{n}\right\| \\
= & \left\|d_{n+1} x_{0}+\left(1-d_{n+1}\right) S y_{n+1}-d_{n} x_{0}-\left(1-d_{n}\right) S y_{n}\right\| \\
\leq & \left\|d_{n+1} x_{0}+\left(1-d_{n+1}\right) S y_{n+1}-d_{n} x_{0}-\left(1-d_{n}\right) S y_{n+1}\right\| \\
& +\left\|d_{n} x_{0}+\left(1-d_{n}\right) S y_{n+1}-d_{n} x_{0}-\left(1-d_{n}\right) S y_{n}\right\| \\
\leq & \left|d_{n+1}-d_{n}\right| \cdot|| x_{0}\left\|+\left|d_{n+1}-d_{n}\right| \cdot\right\| S y_{n+1}\left\|+\left(1-d_{n}\right) \cdot\right\| S y_{n+1}-S y_{n} \| \\
\leq & \left|d_{n+1}-d_{n}\right| \cdot\left\|x_{0}\right\|+\left|d_{n+1}-d_{n}\right| \cdot|| S y_{n+1}\left\|+\left(1-d_{n}\right) \cdot\right\| x_{n+1}-d_{n+1} x_{0}-x_{n}+d_{n} x_{0} \| \\
\leq & 2 M \cdot\left|d_{n+1}-d_{n}\right|+\left(1-d_{n}\right) \cdot\left(|| x_{n+1}-x_{n}\left\|+\left|d_{n+1}-d_{n}\right| \cdot\right\| x_{0} \|\right) .
\end{aligned}
$$

So,

$$
|| x_{n+1}-x_{n} \| \leq \frac{3 M \cdot\left|d_{n+1}-d_{n}\right|}{d_{n}} .
$$

By (i),

$$
\lim _{n \rightarrow \infty}|| x_{n+1}-x_{n} \|=0 .
$$

Furthermore,

$$
\lim _{n \rightarrow \infty}\left\|S y_{n+1}-S y_{n}\right\|=0 .
$$


Next, we have

$$
\begin{aligned}
& \left\|y_{n+1}-y_{n}\right\| \\
= & \left\|\left(a_{n+1} x_{n}+b_{n+1} T_{1} y_{n+1}+c_{n+1} T_{2} y_{n+1}\right)-\left(a_{n} x_{n-1}+b_{n} T_{1} y_{n}+c_{n} T_{2} y_{n}\right)\right\| \\
\leq & \left\|\left(a_{n+1} x_{n}+b_{n+1} T_{1} y_{n+1}+c_{n+1} T_{2} y_{n+1}\right)-\left(a_{n} x_{n}+b_{n} T_{1} y_{n+1}+c_{n} T_{2} y_{n+1}\right)\right\| \\
& +\left\|\left(a_{n} x_{n}+b_{n} T_{1} y_{n+1}+c_{n} T_{2} y_{n+1}\right)-\left(a_{n} x_{n-1}+b_{n} T_{1} y_{n}+c_{n} T_{2} y_{n}\right)\right\| \\
\leq & \left.\left|a_{n+1}-a_{n}\right| \cdot\left\|x_{n}||+\left|b_{n+1}-b_{n}\right| \cdot\right\| T_{1} y_{n+1}\left\|+\left|c_{n+1}-c_{n}\right| \cdot\right\| T_{2} y_{n+1}\right) \| \\
& +a_{n}|| x_{n}-x_{n-1}\left\|+b_{n}|| T_{1} y_{n+1}-T_{1} y_{n}||+c_{n}\right\| T_{2} y_{n+1}-T_{2} y_{n} \| \\
\leq & M \cdot\left(\left|a_{n+1}-a_{n}\right|+\left|b_{n+1}-b_{n}\right|+\left|c_{n+1}-c_{n}\right|\right) \\
& +a_{n}|| x_{n}-x_{n-1}\left\|+b_{n}|| y_{n+1}-y_{n}\right\|+c_{n}|| y_{n+1}-y_{n} \| .
\end{aligned}
$$

This implies that

$$
|| y_{n+1}-y_{n}|| \leq \frac{M \cdot\left(\left|a_{n+1}-a_{n}\right|+\left|b_{n+1}-b_{n}\right|+\left|c_{n+1}-c_{n}\right|\right)}{a_{n}}+|| x_{n}-x_{n-1}|| .
$$

So,

$$
\lim _{n \rightarrow \infty}\left\|y_{n+1}-y_{n}\right\|=0
$$

Besides,

$$
\lim _{n \rightarrow \infty}\left\|y_{n}-x_{n-1}\right\|=\lim _{n \rightarrow \infty}\left\|b_{n}\left(T_{1} y_{n}-x_{n-1}\right)+c_{n}\left(T_{2} y_{n}-x_{n-1}\right)\right\|=0
$$

and

$$
\lim _{n \rightarrow \infty}\left\|y_{n}-S y_{n}\right\|=\lim _{n \rightarrow \infty}\left\|y_{n}-T_{1} y_{n}\right\|=\lim _{n \rightarrow \infty}\left\|y_{n}-T_{2} y_{n}\right\|=0
$$

Let $\phi: C \rightarrow \mathbb{R}$ be defined by $\phi(u):=\mu_{n}\left\|x_{n}-u\right\|$ for each $u \in C$. Clearly, $\phi$ is convex and continuous. Taking $p \in \Omega$ and defining a subset $D$ of $C$ by

$$
D:=\{x \in C:\|x-p\| \leq r\},
$$

where $r:=\max \left\{\left\|x_{0}-p\right\|,\left\|x_{1}-p\right\|\right\}$. Then, $D$ is a nonempty closed bounded convex subset of $C$ and $\left\{x_{n}\right\} \subseteq D$. By Lemma 5.1 ,

$$
C_{\min }:=\left\{z \in D: \varphi(z):=\min _{\gamma \in D} \varphi(\gamma)\right\} \neq \varnothing
$$

Obviously, $C_{\min }$ is a bounded closed convex subset. Following the property of Banach limit $\mu_{n}$, for all $z \in C_{\text {min }}$, we have

$$
\begin{aligned}
\varphi(S z) & =\mu_{n}\left\|x_{n}-S z\right\|^{2} \\
& \leq \mu_{n}\left(\left\|x_{n}-y_{n}\right\|+\left\|y_{n}-S z\right\|\right)^{2} \\
& \leq \mu_{n}\left(\left\|x_{n}-y_{n}\right\|+3\left\|y_{n}-S y_{n}\right\|+\left\|y_{n}-z\right\|\right)^{2} \\
& =\mu_{n}\left\|y_{n}-z\right\|^{2} \\
& \leq \mu_{n}\left(\left\|y_{n}-x_{n}\right\|+\left\|x_{n}-z\right\|\right)^{2} \\
& \leq \mu_{n}\left\|x_{n}-z\right\|^{2}
\end{aligned}
$$

Then, $S z \in C_{\min }$. By Theorem 4 in [1], there exists $\bar{x} \in C_{\min }$ such that $S \bar{x}=\bar{x}$. By Lemma 5.3, 


$$
\mu_{n}\left\langle y-\bar{x}, J\left(x_{n}-\bar{x}\right)\right\rangle \leq 0 \text { for all } y \in C .
$$

Take any $y \in C$ and let $y$ be fixed. Since $\lim _{n \rightarrow \infty}|| x_{n+1}-x_{n} \|=0$, then it follows from the norm-weak* uniformly continuity of the duality mapping $J$ that

$$
\lim _{n \rightarrow \infty}\left(\left\langle y-\bar{x}_{,} J\left(x_{n+1}-\bar{x}\right)\right\rangle-\left\langle y-\bar{x}_{,} J\left(x_{n}-\bar{x}\right)\right\rangle\right)=0 .
$$

By Lemma 5.4,

$$
\lim _{n \rightarrow \infty}\left\langle y-\bar{x}_{,} J\left(x_{n}-\bar{x}\right)\right\rangle \leq 0 \text { for all } y \in C .
$$

By Lemma 5.2,

$$
\begin{aligned}
& \left\|x_{n}-\bar{x}\right\|^{2} \\
= & \left\|d_{n}\left(x_{0}-\bar{x}\right)+\left(1-d_{n}\right)\left(S y_{n}-\bar{x}\right)\right\|^{2} \\
\leq & \left(1-d_{n}\right)^{2}\left\|S y_{n}-\bar{x}\right\|^{2}+2 d_{n}\left\langle x_{0}-\bar{x}, J\left(x_{n}-\bar{x}\right)\right\rangle \\
\leq & \left(1-d_{n}\right)^{2}\left\|y_{n}-\bar{x}\right\|^{2}+2 d_{n}\left\langle x_{0}-\bar{x}, J\left(x_{n}-\bar{x}\right)\right\rangle \\
\leq & \left(1-d_{n}\right)\left\|x_{n-1}-\bar{x}\right\|^{2}+2 d_{n}\left\langle x_{0}-\bar{x}, J\left(x_{n}-\bar{x}\right)\right\rangle .
\end{aligned}
$$

By Lemma 5.5, $\lim _{n \rightarrow \infty}\left\|x_{n}-\bar{x}\right\|=0$. Furthermore, since $T_{1}$ and $T_{2}$ are nonexpansive mappings, we know that $\bar{x}$ is also a fixed point of $T_{1}$ and $T_{2}$. Therefore, the proof is completed.

The following is a special case of Theorem 5.1 when $T_{1}$ and $T_{2}$ are identity mappings.

Theorem 5.2. Let $E$ be a uniformly convex and uniformly smooth Banach space with Opial's condition, $C$ be a nonempty closed convex subset of $E$, and let $S: C \rightarrow C$ be a mapping with condition $(C)$. Let $\left\{d_{n}\right\}$ be a sequence in $(0,1)$. Suppose that $F(S) \neq \varnothing$. Define a sequence $\left\{x_{n}\right\}$ by

$$
\left\{\begin{array}{l}
x_{0} \in C \text { chosen arbitrary, } \\
x_{n}=d_{n} x_{0}+\left(1-d_{n}\right) S x_{n-1}, n \in \mathbb{N} .
\end{array}\right.
$$

Assume that $\lim _{n \rightarrow \infty} d_{n}=0, \sum_{n=1}^{\infty} d_{n}=\infty$, and $\lim _{n \rightarrow \infty} \frac{\left|d_{n+1}-d_{n}\right|}{d_{n}}=0$.. Then, $\lim _{n \rightarrow \infty} x_{n}=\lim _{n \rightarrow \infty} y_{n}=\bar{x}$ for some $\bar{x} \in F(S)$.

\section{Application}

Let $E$ be a reflexive, strictly convex, and smooth Banach space and let $A \subseteq E \times E^{*}$ be a set-valued mapping with range $R(A):=\left\{x^{*} \in E^{*}: x^{*} \in A x\right\}$ and domain $D(A)=\{x \in E: A x \neq \emptyset\}$. Then, the mapping $A$ is said to be monotone if $\left\langle x-y, x^{*}-y^{*}\right\rangle \geq$ 0 whenever $\left(x, x^{*}\right),\left(y, y^{*}\right) \in A$. It is also said to be maximal monotone if $A$ is monotone and there is no monotone operator from $E$ into $E^{*}$ whose graph properly contains the graph of $A$. It is known that if $A \subseteq E \times E^{*}$ is maximal monotone, then $A^{-1} 0$ is closed and convex.

Lemma 6.1. [30] Let $E$ be a reflexive, strictly convex, and smooth Banach space and let $A \subseteq E \times E^{*}$ be a monotone operator. Then, $A$ is maximal monotone if and only if $R$ $(J+r A)=E^{*}$ for all $r>0$.

By Lemma 6.1, for every $r>0$ and $x \in E$, there exists a unique $x_{r} \in D(A)$ such that $J x \in J x_{r}+r A x_{r}$. Hence, define a single valued mapping $J_{r}: E \rightarrow D(A)$ by $J_{r} x=x_{r}$, that 
is, $J_{r}=(J+r A)^{-1} J$ and such $J_{r}$ is called the relative resolvent of $A$. We know that $A^{-1} 0$ $=F\left(J_{r}\right)$ for all $r>0[8]$.

Lemma 6.2. [21] Let $E$ be a uniformly convex and uniformly smooth Banach space and let $A \subseteq E \times E^{*}$ be a maximal monotone operator. Let $J_{r}$ be the relative resolvent of $A$, where $r>0$. If $A^{-10}$ is nonempty, then $J_{r}$ is a relatively nonexpansive mapping on $E$.

By Theorem 4.1 and Lemma 6.2, it is easy to get the following result.

Theorem 6.1. Let $E$ be a uniformly convex and uniformly smooth Banach space with property $(Q)$, and let $C$ be a nonempty closed convex subset of $E$, and let $T_{1}, T_{2}: C \rightarrow$ $C$ be two nonexpansive mappings, and let $A \subseteq E \times E^{*}$ be a maximal monotone operator. Let $\left\{a_{n}\right\},\left\{b_{n}\right\},\left\{c_{n}\right\}$, and $\left\{d_{n}\right\}$ be sequences in $(0,1)$ with and $a_{n}+b_{n}+c_{n}=1$. Suppose that $\Omega:=A^{-1} 0 \cap F\left(T_{1}\right) \cap F\left(T_{2}\right) \neq \varnothing$. Define a sequence $\left\{x_{n}\right\}$ by

$$
\left\{\begin{array}{l}
x_{0} \in C \text { chosen arbitrary and } C_{0}=D_{0}=C, \\
y_{n}=a_{n} x_{n-1}+b_{n} T_{1} y_{n}+c_{n} T_{2} y_{n} \\
z_{n}=J^{-1}\left(d_{n} J y_{n}+\left(1-d_{n}\right) J J_{r} y_{n}\right) \\
C_{n}=\left\{z \in C_{n-1}: \phi\left(z, z_{n}\right) \leq \phi\left(z, y_{n}\right)\right\} \\
D_{n}=\left\{z \in D_{n-1}:\left\|y_{n}-z\right\| \leq\left\|x_{n-1}-z\right\|\right\} \\
x_{n}=\Pi_{C_{n} \cap D_{n}} x_{0}
\end{array}\right.
$$

Assume that $\lim \inf _{n \rightarrow \infty} b_{n}>0, \liminf _{n \rightarrow \infty} c_{n}>0$, and $\lim _{\inf _{n \rightarrow \infty}} d_{n}\left(1-d_{n}\right)>0$.

Then, $\lim _{n \rightarrow \infty} x_{n}=\lim _{n \rightarrow \infty} y_{n}=\lim _{n \rightarrow \infty} z_{n}=\prod_{\Omega} x_{0}$.

\section{Acknowledgements}

This research was supported by the National Science Council of Republic of China.

\section{Author details}

${ }^{1}$ Department of Mathematics, National Changhua University of Education, Changhua 50058, Taiwan ${ }^{2}$ Department of Electronic Engineering, Nan Kai University of Technology, Nantour 54243, Taiwan

\section{Authors' contributions}

L-JL responsible for problem resign, coordinator, discussion, revise the important part, and submit. C-SC is responsible for the important results of this article, discuss, and draft. Z-TY is responsible for discussion and the applications. All authors read and approved the final manuscript.

\section{Competing interests}

The authors declare that they have no competing interests.

Received: 19 August 2011 Accepted: 6 December 2011 Published: 6 December 2011

\section{References}

1. Suzuki, T: Fixed point theorems and convergence theorems for some generalized nonexpansive mappings. J Math Anal Appl. 340, 1088-1095 (2008). doi:10.1016/j.jmaa.2007.09.023

2. Mann, WR: Mean value methods in iteration. Proc Am Math Soc. 4, 506-510 (1953). doi:10.1090/S0002-9939-19530054846-3

3. Soltuz, SM: The backward Mann iteration. Octogon Math Mag. 9(2):797-800 (2001)

4. Xu, HK, Ori, RG: An implicit iteration process for nonexpansive mappings. Numer Funct Anal Optim. 22, 767-773 (2001). doi:10.1081/NFA-100105317

5. Khan, SH, Yildirim, I, Ozdemir, M: Convergence of an implicit algorithm for two families of nonexpansive mappings. Comput Math Appl. 59, 3084-3091 (2010). doi:10.1016/j.camwa.2010.02.029

6. Chidume, CE, Shahzad, N: Strong convergence of an implicit iteration process for a finite family of nonexpansive mappings. Nonlinear Anal. 65, 1149-1156 (2005)

7. Fukhar-ud-din, H, Khan, $\mathrm{SH}$ : Convergence of iterates with errors of asympotically quasi-nonexpansive mappings and applications. J Math Anal Appl. 328, 821-829 (2007). doi:10.1016/j.jmaa.2006.05.068

8. Takahashi, W: Nonlinear Functional Analysis-Fixed Point Theory and its Applications. Yokohama Publishers Inc Yokohama (2000)

9. Hao, Y, Cho, SY, Qin, X: Some weak convergence theorems for a family of asymptotically nonexpansive nonself mappings. Fixed Point Theory Appl2010. Article ID 218573, 11

10. Xu, HK: Inequalities in Banach spaces with applications. Nonlinear Anal. 16, 1127-1138 (1991). doi:10.1016/0362-546X(91) 90200-K

11. Schu, J: Weak and strong convergence to fixed points of asymptotically non-expansive mappings. Bull Austral Math Soc. 43, 153-159 (1991). doi:10.1017/S0004972700028884 
12. James, RC: Inner products in normed linear spaces. Bull Am Math Soc. 53, 559-566 (1947). doi:10.1090/50002-99041947-08831-5

13. Nilsrakoo, W, Saejung, S: Strong convergence theorems by Halpern-Mann iterations for relatively nonexpansive mappings in Banach spaces. Appl Math Comput. 217, 6577-6586 (2011). doi:10.1016/j.amc.2011.01.040

14. Alber, Yal: Metric and generalized projection operators in Banach spaces: properties and applications. Theory and Applications of Nonlinear Operators of Accretive and Monotone Type. pp. 15-50.Dekker, New York (1996)

15. Kamimura, S, Takahashi, W: Strong convergence of a proximal-type algorithm in a Banach space. SIAM J Optim. 13, 938-945 (2002). doi:10.1137/S105262340139611X

16. Bruck, RE: Properties of fixed point sets of nonexpansive mappings in Banach spaces. Trans Am Math Soc. 179, 251-262 (1973)

17. Browder, FE: Fixed point theorems for noncompact mappings in Hilbert spaces. Proc Nat Acad Sci USA. 53, 1272-1276 (1965). doi:10.1073/pnas.53.6.1272

18. Garcia-Falset, J, Llorens-Fuster, E, Suzuki, T: Fixed point theory for a class of generalized nonexpansive mappings. J Math Anal Appl. 375, 185-195 (2011). doi:10.1016/j.jmaa.2010.08.069

19. Karapinar, E, Taş, K: Generalized (C)-conditions and related fixed point theorems. Comput Math Appl. 61, 3370-3380 (2011). doi:10.1016/j.camwa.2011.04.035

20. Matsushita, S, Takahashi, W: Weak and strong convergence theorems for relatively nonexpansive mappings in Banach spaces. Fixed Point Theory Appl 37-47 (2004). 2004

21. Matsushita, S, Takahashi, W: A strong convergence theorem for relatively nonexpansive mappings in a Banach space. J Approx Theory. 134, 257-266 (2005). doi:10.1016/j.jat.2005.02.007

22. Kirk, WA, Panyanak, B: A concept of convergence in geodesic spaces. Nonlinear Anal. 68, 3689-3696 (2008). doi:10.1016/ j.na.2007.04.011

23. Kohsaka, F, Takahashi, W: Fixed point theorems for a class of nonlinear mappings related to maximal monotone operators in Banach spaces. Arch Math. 91, 166-177 (2008). doi:10.1007/s00013-008-2545-8

24. Takahashi, W, Takeuchi, Y, Kubota, R: Strong convergence theorems by hybrid methods for families of nonexpansive mappings in Hilbert spaces. J Math Anal Appl. 341, 276-286 (2008). doi:10.1016/j.jmaa.2007.09.062

25. Takahashi, W, Zembayashi, K: Strong convergence theorem by a new hybrid method for equilibrium problems and relatively nonexpansive mappings. Fixed Point Theory Appl 11 (2008). Article ID 528476

26. Aubin, JP, Ekeland, I: Applied Nonlinear Analysis. A Wiley-Interscience Publication John Wiley and Sons, Canada (1984)

27. Song, Y, Chen, R: Strong convergence of an iterative method for non-expansive mappings. Math Nachr. 281, 1196-2204 (2008). doi:10.1002/mana.200510670

28. Shioji, N, Takahashi, W: Strong convergence of approximated sequences for non-expansive mappings in Banach spaces. Proc Am Math Soc. 125, 3641-3645 (1997). doi:10.1090/50002-9939-97-04033-1

29. Xu, HK: Iterative algorithm for nonlinear operators. J London Math Soc. 2, 240-256 (2002)

30. Rockafellar, RT: On the maximality of sums of nonlinear monotone operators. Trans Am Math Soc. 149, 75-88 (1970). doi:10.1090/S0002-9947-1970-0282272-5

doi:10.1186/1687-1812-2011-96

Cite this article as: Lin et al: Weak and strong convergence theorems of implicit iteration process on Banach spaces. Fixed Point Theory and Applications 2011 2011:96.

\section{Submit your manuscript to a SpringerOpen ${ }^{\odot}$ journal and benefit from:}

- Convenient online submission

- Rigorous peer review

- Immediate publication on acceptance

- Open access: articles freely available online

- High visibility within the field

- Retaining the copyright to your article

Submit your next manuscript at $\gg$ springeropen.com 